\title{
Modeling of the roll wear and material damage during high-ratio differential speed rolling of aluminium alloy 7075
}

\author{
Alexander Pesin ${ }^{a}$, Denis Pustovoytov, Natalya Lokotunina \\ Nosov Magnitogorsk State Technical University, Department of Material processing, 455000, Magnitogorsk, Lenin prospect, 38, Russia
}

\begin{abstract}
The technology of high-ratio differential speed rolling (HRDSR) with high contact friction can be used for production of aluminium alloys with UFG structure. But a high friction coefficient is not desirable because of the increasing of the material damage. The paper presents a numerical analysis of the rolls wear and material damage during HRDSR of aluminium alloy 7075. The FEM was used to calculate the rolls wear by Archard's model and material damage by normalized Cockroft-Latham model.
\end{abstract}

\section{Introduction}

Aluminium and its alloys play a key role in modern engineering since they are the most used non-ferrous materials [1]. They have been widely used as structural materials in aerospace, automotive and other industries due to low density and high specific strength. Conventional approaches to increasing strength properties of aluminum alloys based on modification of their chemistry by alloying and on development of heat treatment and thermomechanical treatment methods are almost exhausted. A more efficient way to further increase strength and other operational and technological properties of aluminium alloys is to form an ultrafine grain (UFG) structure using severe plastic deformation (SPD) methods. This can be achieved through any of a number of different processes such as equal channel angular pressing, multi-directional forging, accumulated roll bonding, high-pressure torsion, twist extrusion and high-ratio differential speed rolling (HRDSR) in which the speeds of the upper and lower rolls are different. Since the HRDSR is a continuous process, it has great potential for industrial production of ultrafine grained aluminium alloys [2-7].

It is well known that the mechanism of SPD during HRDSR comes from its large equivalent strain, which is composed of compressive strain and additional shear strain. For a given thickness reduction, the equivalent strain is proportional to shear strain because the normal strain is the same. Shear strain during HRDSR can be presented as tangent of shear angle. During HRDSR shear angle strongly depends on opposite contact friction forces operated in the deformation zone. High shear strain through thickness of the sheet can be obtained only with a high value of friction coefficient [8-11]. So HRDSR should be carried out without lubrication. But a high friction coefficient is not desirable, not only because

\footnotetext{
a Corresponding author: pesin@bk.ru
}

of the energy wasted but also because of the wear and damage increasing of the sliding system [12].

It is well accepted that adhesive, abrasive, fatigue, and corrosive wear may each play a role in cold rolling wear. The wear patterns may exist separately or in a mixed regime.

Experimental investigations of the roll wear during HRDSR have been the subject of several publications.In [13] an investigation of the wear mechanisms in the cold rolling of aluminium strip was reported. The effects of the pass reduction, the viscosity of the lubricant and the additives in the lubricant on wear were researched by measuring the relative mass wear rate and by observation of the rolled surface by means of optical microscopy and scanning electron microscopy.

HRDSR with high contact friction is a process that may be limited by damage and edge cracks of the rolled Al sheet.Therefore an important concern in the HRDSR of high-strength $\mathrm{Al}$ alloys is whether the desired strain can be performed without any fracture of the material. Fracturing by ductile damage occurs in HRDSR process due to the development of microcracks associated with high shear strain.In order to investigate this phenomenon, simulation programs based on the Cockroft-Latham fracture model is usedin engineering analysis [14].The Cockcroft-Latham fracture criterion assumes that the maximum principal stress is the most relevant in the initiation of fracture. The criterion is defined in terms of traction plastic work associated with the principal stress along the path of the equivalent plastic strain [14].

Many researchers have used the finite element method to investigate the influence of cold rolling process parameters (e.g., thickness reduction, friction conditions) on the damage and edge cracks of the rolled $\mathrm{Al}$ sheets. A computational and experimental study of damage evolution during conventional cold rolling of aluminium alloys was reported in [15]. Although many studies have 
been done, there are no numerical data on the effect of the HRDSR process parameters on the roll wear and damage of the rolled Al sheets. The goal of this research is the numerical simulation and comparison of the rolls wear and material damage during conventional cold rolling and HRDSR. The results of investigation can be used to optimize the high-ratio differential speed rolling process to improve the quality of UFG aluminium sheets.

\section{Research method}

Software DEFORM 3D, based on finite element method (FEM), was used to analyze the three-dimensional metal flow during conventional cold rolling and HRDSR. DEFORM 3D is an effective tool that allows to predict the character of the metal flow, roll wear and material damage during cold rolling.

The roll wear phenomenon in cold rolling is very complex. Many wear mechanisms exist described as adhesive wear, abrasive wear, diffusive wear, fatigue wear, etc. DEFORM 3D offers two kinds of tool wear model: Archard model and Usui model. Archard abrasive wear model can be viewed as a primary wear mechanism where the wear of the sliding system greatly differ in hardness. Usui model is applicable to the processes where diffusion is a major contributor to wear. Therefore, we choose Archard as the mathematical model of roll wear simulation analysis. Refer to Archard's wear model (1) it is clear that the interface pressure and sliding velocity are the main factors to affect the wear of work rolls.

$$
\mathrm{w}=\int \mathrm{K} \frac{\mathrm{P}^{\mathrm{a}} \mathrm{V}^{\mathrm{b}}}{\mathrm{H}^{\mathrm{c}}} \mathrm{dt},
$$

where $\mathrm{w}$ - wear depth, $\mathrm{mm}$; $\mathrm{P}$ - interface pressure, $\mathrm{MPa}$; $\mathrm{V}$ - sliding velocity, $\mathrm{m} / \mathrm{s} ; \mathrm{H}$ - Rockwell $\mathrm{C}$ hardness of roll material; $\mathrm{a}=1, \mathrm{~b}=1, \mathrm{c}=2$ - calibration coefficients (standard values for common tool steels); $\mathrm{K}$ - wear factor ( $\mathrm{K}=5 \times 10^{-7}$ is a typical value for cold rolling processes).

Damage in the cold rolling process is a three dimensional phenomenon that requires a $3 \mathrm{D}$ model for accurate predictions. In this study, the normalized Cockroft-Latham damage model was applied to predict the material fracture during HRDSR. The CockroftLatham model defines a damage parameter $\mathrm{D}$ as shown in following equation:

$$
\mathrm{D}=\int^{\bar{\varepsilon}} \frac{\sigma_{\max }}{\bar{\sigma}} \mathrm{d} \bar{\varepsilon} \leq \mathrm{C},
$$

where $\sigma_{\max }-$ the maximum positive principal stress; $\mathrm{c}^{-}$ the equivalent plastic strain; $\bar{\sigma}-$ the effective stress; $\mathrm{C}-$ the critical damage value at fracture.

This model determines the likelihood of fracture from tensile plastic deformation, by consideration of the plastic work to failure. When the damage value reaches the constant $\mathrm{C}$, the material is fractured. While it is necessary to determine the constant $\mathrm{C}$ by experimentation, a general rule is that materials with very good workability will fracture at a damage value between 0.8 and 1.0 and materials with poor workability will fracture at values between 0.3 and 0.4 [15].
The modeling of the process was performed at room temperature taking into account the increment of the metal's temperature due to the thermal effect of deformation. Heat transfer coefficient at the interface in all calculation variants was set constant and equal to $11000 \mathrm{~W} /\left(\mathrm{m}^{2} \times \mathrm{K}\right)$. The work rolls were assumed as rigid. High-carbon chromium alloy steel AISI D2 was chosen as a material for rolls. In the HRDSR process the temperature of the rolls does not exceed $50^{\circ} \mathrm{C}$. So the hardness (62 HRC) of the AISI D2 rolls was a constant. Work roll radii were set constant and equal to $100 \mathrm{~mm}$. A Coulomb friction model was used between rolls and sheet, which assumes that no relative motion occurs if the equivalent frictional stress is less than a critical value. The friction coefficient varied within the following range: $0.1 \ldots 0.4$. The thickness reduction per pass was $50 \%$ in all calculation variants. Aluminium alloy 7075 from DEFORM 3D material library was chosen as a hardened rigid-plastic material for sheet.

Differential speed rolling process was carried out at three different angular speeds of the bottom roll: $1 ; 5 ; 10$ $\mathrm{rad} / \mathrm{s}$. It corresponded to $0.1 \mathrm{~m} / \mathrm{s}, 0.5 \mathrm{~m} / \mathrm{s}$ and $1.0 \mathrm{~m} / \mathrm{s}$ of circumferential speed. Speed of the top roll was reduced by $10 ; 30 ; 50 \%$ during asymmetric rolling. Sheet with initial dimensions of $2.0 \times 20.0 \times 50.0 \mathrm{~mm}$ was meshed with 14220 brick elements. Rolls were meshed with 117000 tetrahedral elements. The boundary conditions were set in order to constrain the mid-width plane (symmetry plane) of the sheet along the rolling direction.

In the course of simulation of conventional cold rolling and HRDSR the influence of the process parameters on roll wear and material damage was studied. In all calculation variants roll wear depth corresponds to the one revolution of the roll.

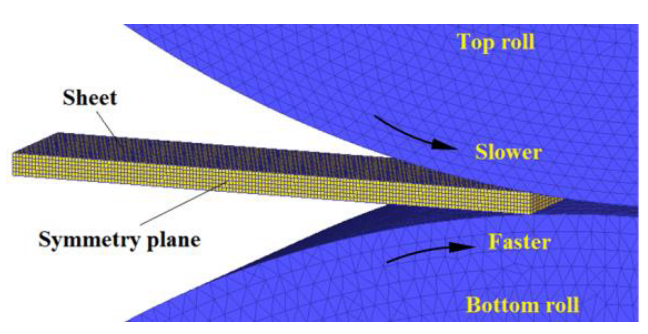

Figure. 1. FEM model of the process

\section{Simulation results and discussion}

Fig. 2 shows the interrelation of roll wear and friction coefficient during conventional (symmetric) cold rolling and HRDSR. The larger the contact friction is, the more serious is roll wear for conventional rolling. It can be explained by increasing of the interface pressure. The wear of both rolls is the same for conventional cold rolling. However, the roll wear is significantly differs for HRDSR. Increasing the contact friction coefficient from 0.1 to 0.4 leads to increasing of the roll wear up to 1.9 times for the top roll. But it is decreased up to 2.0 times for the bottom roll (Fig. 2). Decreasing of the friction coefficient less than 0.3 is not desirable because of significantly decreasing of the shear strain during HRDSR. 


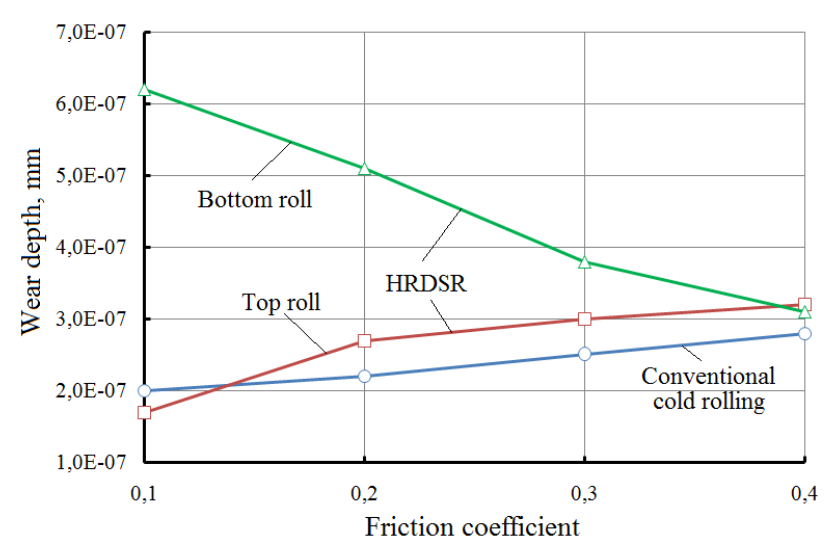

Figure. 2. Interrelation of rolls wear and friction coefficient during conventional cold rolling and HRDSR (thickness reduction is $50 \%$; rolls speed ratio is $50 \%$; rolling speed is 1.0 $\mathrm{m} / \mathrm{s})$

Fig. 3 shows the fields of roll wear depth ( $\mathrm{mm})$ during conventional cold rolling and HRDSR. By analyzing the results of simulation, it can be inferred that at a low friction coefficient the wear of bottom (fast) roll is much higher during HRDSR. It can be explained by different influence of the pressure and sliding velocity on the contact surfaces.

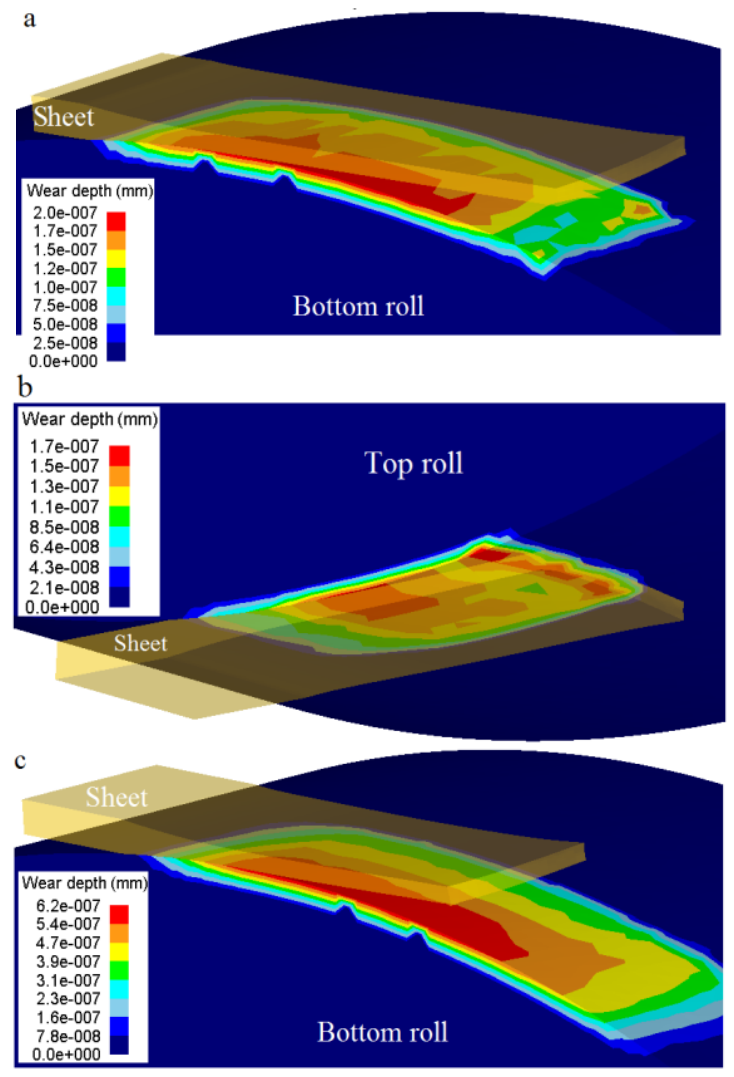

Figure 3. Rolls wear during conventional cold rolling (a) and $\operatorname{HRDSR}(\mathrm{b}, \mathrm{c})$ (thickness reduction is $50 \%$; rolling speed is $1.0 \mathrm{~m} / \mathrm{s}$; friction coefficient is 0.1 ; rolls speed ratio is $50 \%$ for HRDSR)

Increasing the friction coefficient leads to decreasing of the sliding velocity on the contact with both rolls during conventional cold rolling (Fig. $4 \mathrm{a}, \mathrm{b}$ ). At the same time the interface pressure is increased significantly
(Fig. 6a, b). As a result, roll wear depth is increased during conventional cold rolling.

Another situation is during HRDSR. On the one hand, increasing friction coefficient leads to increasing of the sliding velocity on the contact with the top (slow) roll (Fig. 4c, d). On the other hand it leads to decreasing of the sliding velocity on the contact with the bottom (fast) roll (Fig. 5). Increasing the friction coefficient leads to insignificant increasing of the interface pressure during HRDSR (Fig. 6c, d). As a result, roll wear depth is increased for the top roll and it is decreased for the bottom roll.
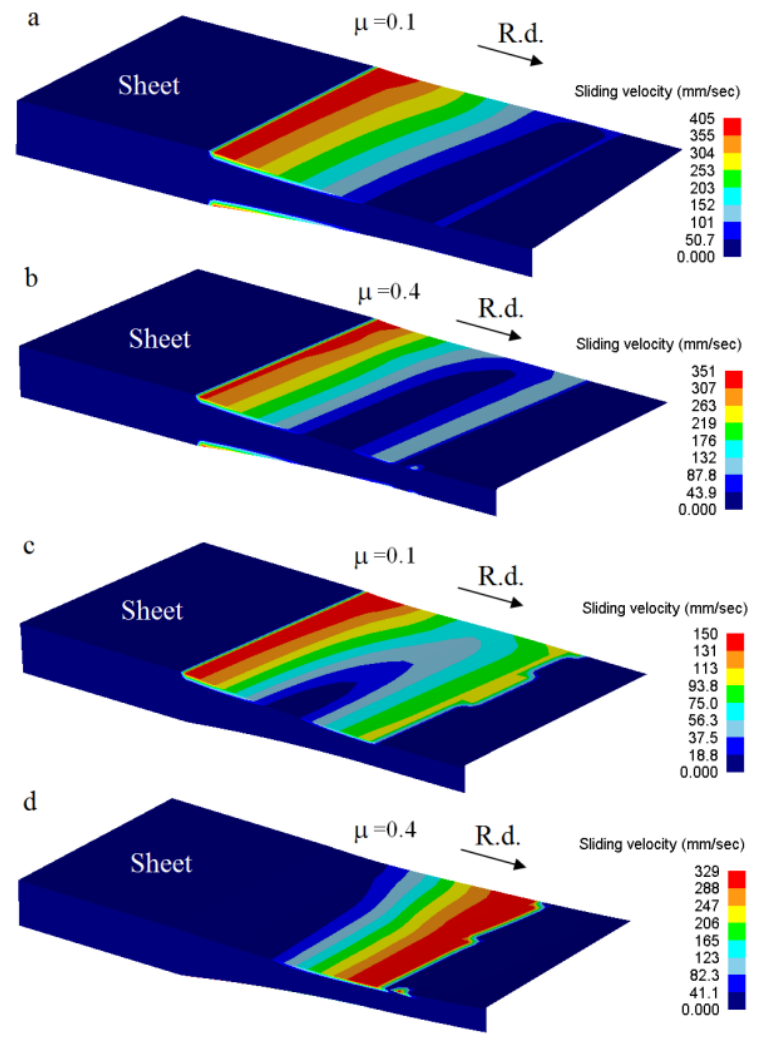

Figure 4. Sliding velocity on the contact with the top roll during conventional cold rolling $(a, b)$ and $\operatorname{HRDSR}(\mathrm{c}, \mathrm{d})$ (thickness reduction is $50 \%$; rolling speed is $1.0 \mathrm{~m} / \mathrm{s}$; rolls speed ratio is $50 \%$ for HRDSR; R.d. - rolling direction)
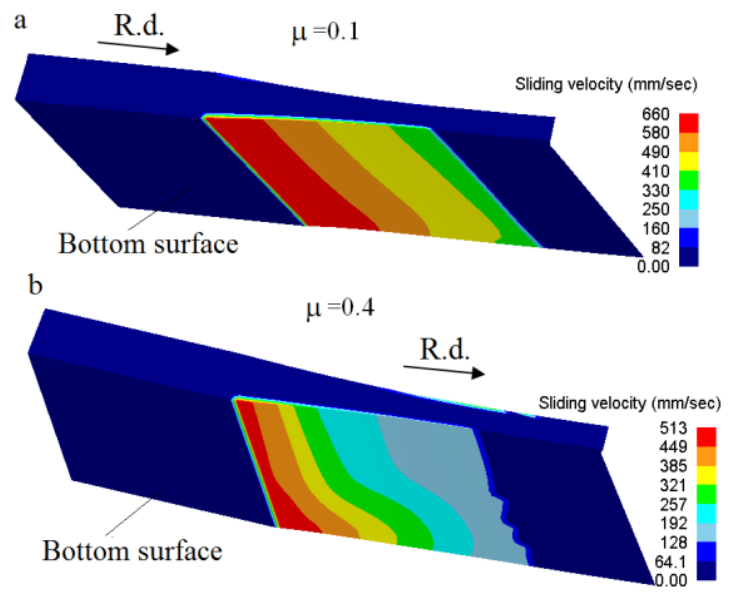

Figure 5. Sliding velocity on the contact with the bottom roll during HRDSR with friction coefficient 0.1 (a) and 0.4 (b) (thickness reduction is $50 \%$; rolling speed is $1.0 \mathrm{~m} / \mathrm{s}$; rolls speed ratio is $50 \%$ ) 

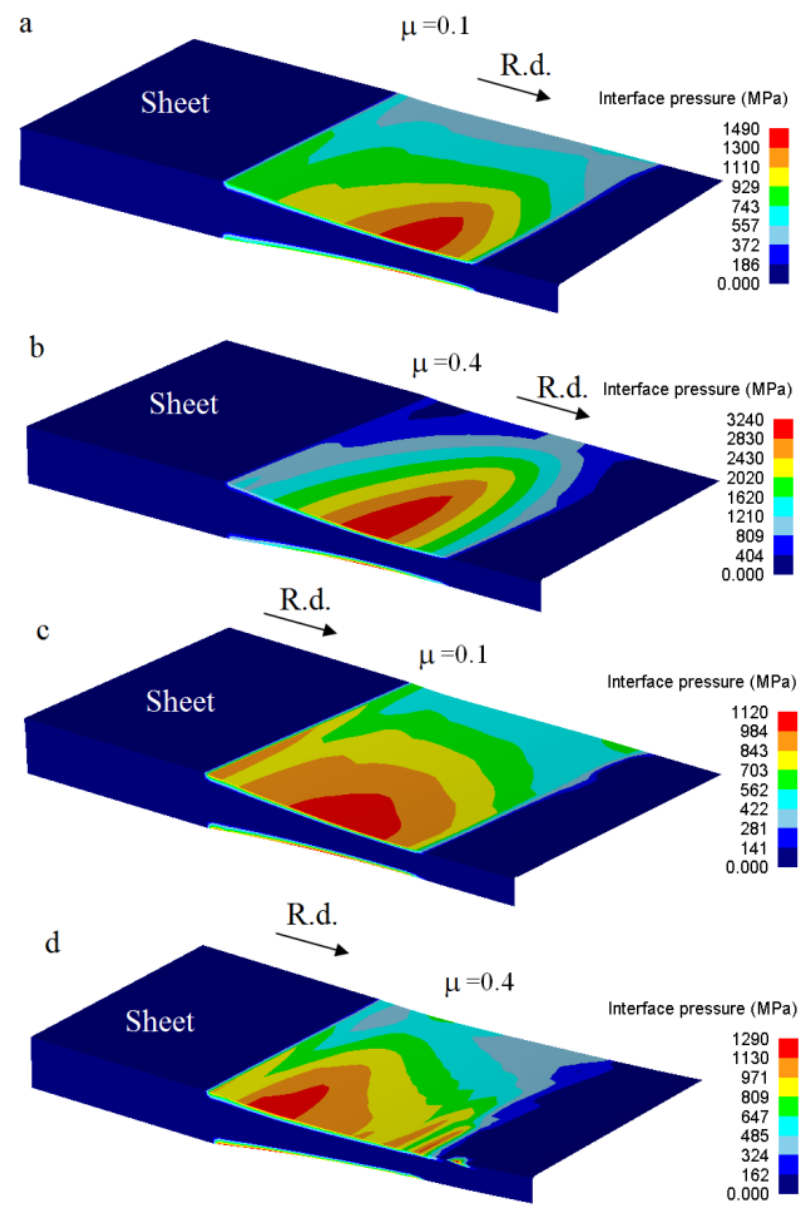

Figure 6. Interface pressure during conventional cold rolling (a, b) and HRDSR (c, d) (thickness reduction is 50\%; rolling speed is $1.0 \mathrm{~m} / \mathrm{s}$; rolls speed ratio is $50 \%$ for HRDSR)

Decreasing the rolling speed from $1.0 \mathrm{~m} / \mathrm{s}$ to $0.1 \mathrm{~m} / \mathrm{s}$ leads to decreasing of the roll wear (Fig. 7).

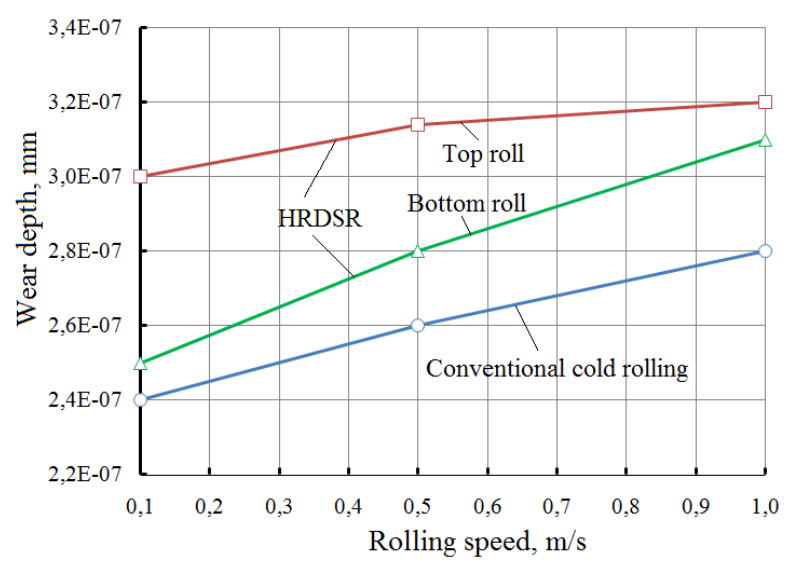

Figure 7. Interrelation of roll wear and rolling speed during conventional cold rolling and HRDSR (thickness reduction is $50 \%$; friction coefficient is 0.4 ; rolls speed ratio is $50 \%$ )

Higher is the speed ratio, more serious is roll wear depth (Fig. 8). Increasing the rolls speed ratio till 50\% leads to increasing of the wear up to 1.14 times for the top roll and up to 1.10 times for the bottom roll when friction coefficient is 0.4 . Increasing the rolls speed ratio more than thickness reduction per pass $(50 \%)$ leads to significant increasing of the wear of the bottom (fast) roll up to 2.2 times.

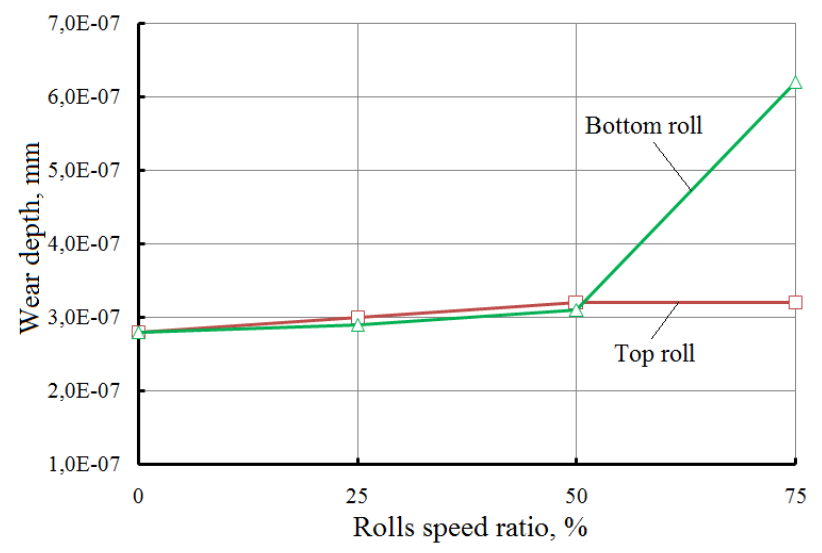

Figure 8. Interrelation of roll wear and rolls speed ratio during HRDSR (thickness reduction is $50 \%$; friction coefficient is 0.4 ; rolling speed is $1.0 \mathrm{~m} / \mathrm{s}$ )

The friction coefficient and rolls speed ratio are the most two important factors that influence on the damage and fracture of $\mathrm{Al}$ sheets during HRDSR in comparison with conventional cold rolling.

Fig. 9 shows the contours of the damage parameter D according to the Eq. (2) with the normalized CockroftLatham model for conventional cold rolling. It can be seen that the damage concentration occurs on the free edge after exiting the rolls, with the maximum at the middle of the sheet thickness. It corresponds to regions where the tensile principal stresses occur. Very high tensile stresses also occur in the rear noncontact deformation zone (highlighted by arrow in Fig. 9b).

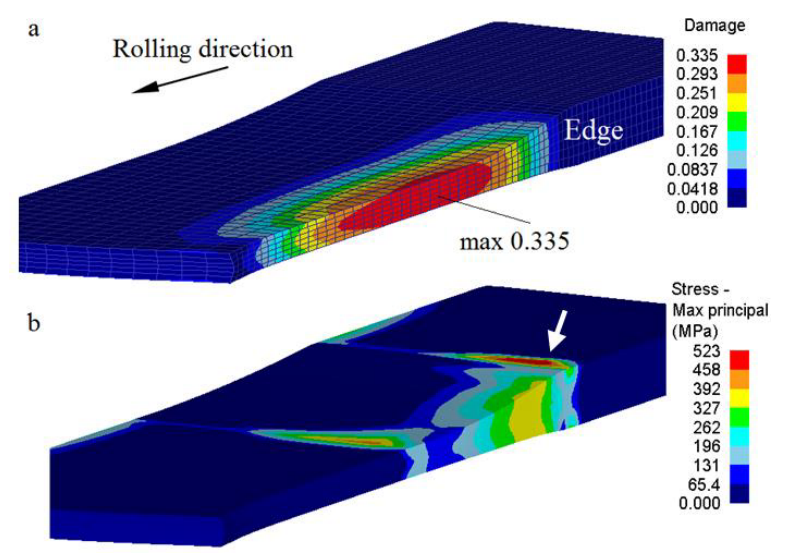

Figure 9. Field of the material damage (a) and tensile stresses (b) during conventional cold rolling (friction coefficient is 0.1 ; thickness reduction is $50 \%$; rolling speed is $1.0 \mathrm{~m} / \mathrm{s}$ )

HRDSR leads to increasing of the material damage (Fig. 10) in comparison with conventional cold rolling because of additional shear strain. It should be noted that damage parameter $\mathrm{D}$ is higher for the bottom surface of the sheet. Higher tensile stresses are found directly under the bottom roll in the longitudinal direction at the edge where stress concentration is observed. Asymmetry of HRDSR process is the cause of the sheet curvature. It also leads to increasing of the tensile stresses in the bottom surface of the sheet. Very high tensile stresses 
occur in the front and rear noncontact deformation zones (highlighted by arrows in Fig. 10b). FEM simulations give damage parameter values very close to that needed for fracture.
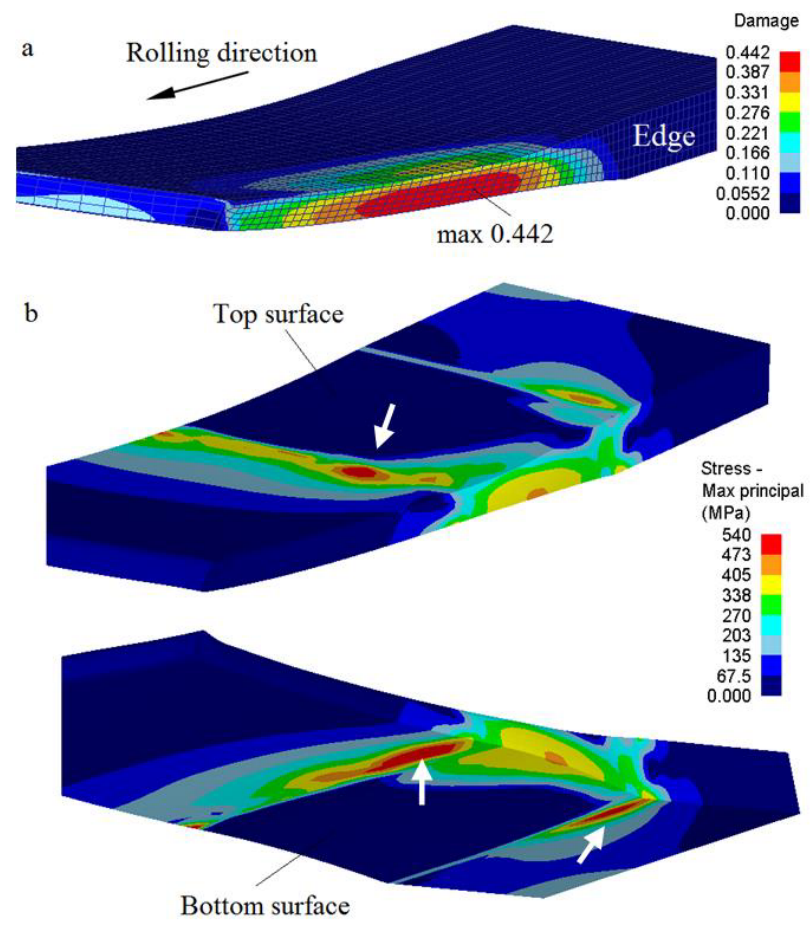

Figure 10. Field of the material damage (a) and tensile stresses (b) during HRDSR (friction coefficient is 0.4; thickness reduction is $50 \%$; rolling speed is $1.0 \mathrm{~m} / \mathrm{s}$; rolls speed ratio is $50 \%$ )

Contact friction is one of the main factors that affect the material damage during cold rolling. Increasing the friction coefficient leads to increasing of the material damage from 0.335 to 0.364 for conventional rolling and from 0.347 to 0.442 for HRDSR (Fig. 11). The damage is also increased when the rolls speed ratio is increased. Decreasing of the friction coefficient is beneficial to reduce the edge damage, but it also leads to significantly decreasing of the shear strain during HRDSR.

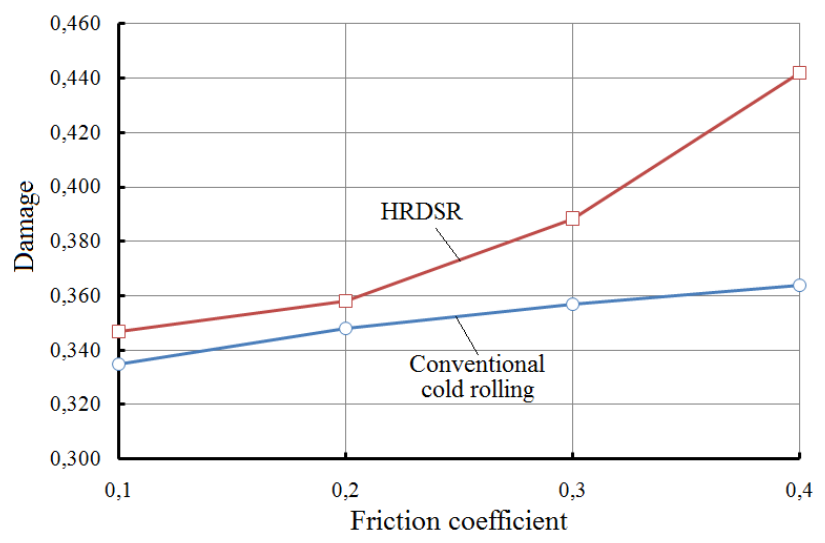

Figure 11. Interrelation of material damage and friction coefficient during conventional rolling and HRDSR (thickness reduction is $50 \%$; rolls speed ratio is $50 \%$; rolling speed is $1.0 \mathrm{~m} / \mathrm{s}$ )

\section{CONCLUSIONS}

The numerical simulation allowed to carry out a comparison between conventional cold rolling and HRDSR in order to highlight differences in the roll wear and material damage imparted by each processes.

Increasing the friction coefficient leads to decreasing of the sliding velocity and to increasing of the pressure on the contact with both rolls during conventional cold rolling. As a result, roll wear depth is increased during conventional cold rolling.

Another situation is during HRDSR. On the one hand, increasing friction coefficient leads to increasing of the sliding velocity on the contact with the top (slow) roll. On the other hand it leads to decreasing of the sliding velocity on the contact with the bottom (fast) roll. Increasing the friction coefficient leads to insignificant increasing of the interface pressure during HRDSR. As a result, roll wear depth is increased for the top (slow) roll and it is decreased for the bottom (fast) roll.

Increasing the friction coefficient leads to increasing of the material damage during HRDSR. The damage is also increased when the rolls speed ratio is increased. Damage is higher for the bottom surface of the sheet where higher tensile stresses were found. FEM simulations give damage parameter values very close to that needed for fracture of Al 7075.

The results of simulation can be used to optimize the HRDSR process to improve the quality of UFG aluminium sheets. Further experimental investigation of the roll wear and material damage during HRDSR is required.

\section{ACKNOWLEDGEMENTS}

The study was supported by a grant of the Russian Science Foundation (project No15-19-10030)

\section{REFERENCES}

1. I. Sabirov, M.Yu. Murashkin, R.Z.Valiev, Materials Science \& Engineering A. 560 (2013) 1-24

2. Y.H. Ji, J.J. Park, W.J. Kim, Materials Science and Engineering: A. 454-455 (2007) 570-574

3. Y.H. Ji, J.J. Park, Materials Science and Engineering: A. 499 (2009) 14-17

4. J. Jiang, Y. Ding, F. Zuo, A. Shan, Scripta Materialia. 60 (2009) 905-908

5. F. Zuo, J. Jiang, A. Shan, Transactions of Nonferrous Metals Society of China, 18 (2008) 774-777

6. Q. Cui, K. Ohori, Materials Science and Technology. 16 (2000) 1095-1101

7. W.J. Kim, B.G. Hwang, M.J. Lee, Y.B. Park, Journal of Alloys and Compounds. 509 (2011) 8510-8517

8. A. Pesin, D. Pustovoytov, Key Engineering Materials. 622-623 (2014) 929-935

9. A. Pesin, M. Chukin, A. Korchunov, D. Pustovoytov, Key Engineering Materials. 622-623 (2014) 912-918

10. A. Pesin, A. Korchunov, D. Pustovoytov, Key Engineering Materials. 685 (2016) 162-166 
11. M. Sverdlik, A. Pesin, D. Pustovoytov, A. Perekhozhikh, Advanced Materials Research. 742 (2013) 476-481

12. A. Pesin, D. Pustovoytov, T. Shveyova, M. Sverdlik, MATEC Web of Conferences. 26 (2015) 1-4

13. Zhang Hui, Journal of Materials Processing Technology. 31 (1992) 235-243

14. H. Yu, et al., Scientific reports. 5 (2015) 1-9

15. S. Ghosh, M. Li, D. Gardiner, Journal of Manufacturing Science and Engineering. 126 (2004) $74-82$ 